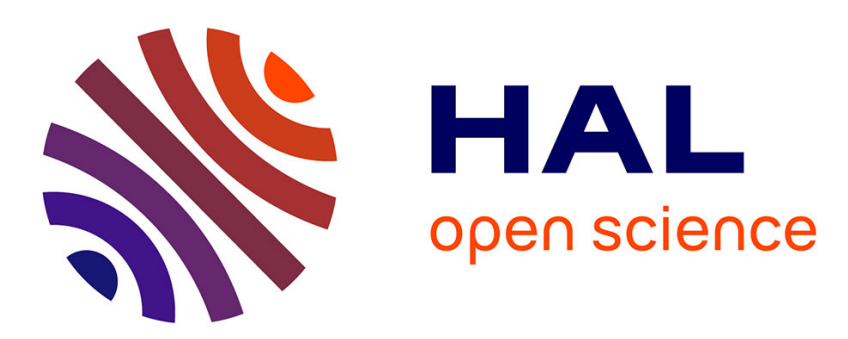

\title{
Aspectuo-temporal underspecification in Anindilyakwa: descriptive, theoretical, typological and quantitative issues
}

Patrick Caudal, James Bednall

\section{- To cite this version:}

Patrick Caudal, James Bednall. Aspectuo-temporal underspecification in Anindilyakwa: descriptive, theoretical, typological and quantitative issues. 2021. hal-03508953

\section{HAL Id: hal-03508953 \\ https://hal.science/hal-03508953}

Preprint submitted on 3 Jan 2022

HAL is a multi-disciplinary open access archive for the deposit and dissemination of scientific research documents, whether they are published or not. The documents may come from teaching and research institutions in France or abroad, or from public or private research centers.
L'archive ouverte pluridisciplinaire HAL, est destinée au dépôt et à la diffusion de documents scientifiques de niveau recherche, publiés ou non, émanant des établissements d'enseignement et de recherche français ou étrangers, des laboratoires publics ou privés. 


\section{Aspectuo-temporal underspecification in Anindilyakwa: de- scriptive, theoretical, typological and quantitative issues}

1 CNRS \& University of Paris; patrick.caudal@u-paris.fr

2 Batchelor Institute of Indigenous Tertiary Education \& Australian National University; james.bednall@anu.edu.au

Citation: Caudal, Patrick and James Bednall. 2022. Title. Languages 6: $\mathrm{x}$. https://doi.org/10.3390/xxxxx

Academic Editor: Firstname Lastname

Received: date

Accepted: date

Published: date

Publisher's Note: MDPI stays neutral with regard to jurisdictional claims in published maps and institutional affiliations.

Copyright: $\odot 2021$ by the authors. Submitted for possible open access publication under the terms and conditions of the Creative Commons Attribution (CC BY) license (https://creativecommons.org/license s/by/4.0/).

\begin{abstract}
So-called 'zero' or 'null' tenses have often been characterized as functionally deficient forms, deprived of any inherent content. In this paper, we will focus on the semantics of a morphophonologically null inflectional verbal paradigm in Anindilyakwa (Groote Eylandt, N.T., Australia, which is both temporally and aspectually underspecified. Through a quantitative corpus study conducted in the paper, we establish that 'zero inflection' in this language, contra prior works on such tenses in general (e.g. Bybee 1990) and in Anindilyakwa in particular (Bednall 2019), presents various degrees of sensitivity to traditional Vendlerian aspectual parameters. We show that while telicity is not a significant predictor for the temporal interpretation of zero-inflected Anindilyakwa verbs, and dynamicity is a good but not very good predictor, only a very broad opposition between change-of-state (including qua boundedness) and non-change-of-state, or perfective/imperfective, gives very significant biases towards past vs. present anchoring. We also show that atomic telicity is the only categorical Aktionsart predictor for temporal anchoring in this context correctly predict the temporal anchoring of such verbs, and stativity is not biased towards present interpretations, thereby questioning currently received typological theories of the semantics of so-called 'zerotenses' / aspectuo-temporally underspecified tenses.
\end{abstract}

Keywords: underspecified tenses; null tense; aspect; present perfective paradox; Australian languages

\section{Introduction}

So-called 'tenselessness' has attracted considerable theoretical attention over the past two decades, especially in Indigenous languages of the Americas. Some of the earliest mentions of this phenomenon were found in grammars of Mayan languages (Craig 1977; England 1983), and the first extensive theoretical account was offered in J. Bohnemeyer's seminal study of Yukatek Maya (Bohnemeyer 2002)see also (Bohnemeyer 2009). Other families of American Indigenous languages were also noted for exhibiting various kinds of tenselessness, as early as (Baker \& Travis 1997) account of Mohawk 'modals' (but see also works from the University of British Columbia group; (Matthewson 2006) on Salish), work by J. Tonhauser and others on Amazonian languages, such as Guarani (Tonhauser 2006; Tonhauser 2011; Pancheva \& Zubizarreta 2020), and research on Mesoamerican languages (cf. (Toosarvandani 2021))). Outside of the Americas, tenselessness has also been identified in Inuit languages (e.g. West Greenlandic; (Shaer 2003; Bittner 2005; Bittner 2008), but also Chinese ((Lin 2003; Lin 2010), Vietnamese (Duffield 2007; Bui 2019), Korean and Japanese (Lee \& Tonhauser 2010), Hausa (Mucha 2012; Mucha 2013) and Samoan (Bochnak 2016; Bochnak, Hohaus \& Mucha 2019), among others. So-called 'tenselessness' has also been noted in various Creoles \& Pidgins (cf. e.g. (Singler 1990). 'Tenseless' languages, i.e. languages lacking inflectional temporal categories, are generally argued to rely instead on aspectual markers, lexical aspectual class information and contextual 
information to determine the temporal anchoring of utterances (cf. e.g. (Tonhauser 2015). 'Superficially tenseless' languages have also been contrasted with 'deeply tenseless' languages following (Matthewson 2006) seminal proposals. Many analyses of so-called tenselessness are hotly debated (see e.g. (Alotaibi 2020) for arguments against tenseless approaches to some varieties of Arabic, and (Chen \& Husband 2018) for Chinese).

While 'tenselessness', or rather what we will refer to as temporal functional deficiency from the point of view of form-meaning pairings, is often associated with entire tenseaspect systems in many accounts, it has also been claimed to associate with specific forms in certain languages (cf. e.g. (Ritter \& Wiltschko 2014). This corresponds either to tense marking being optional (cf. e.g. (Tagliamonte \& Poplack 1993), or to the existence of socalled 'null' or 'zero' inflections (discussed below), contrasting with non-null inflections, in a given language. We claim that Anindilyakwa is such a language. Although not a tenseless language as a whole (Anindilyakwa undoubtedly possesses inflectionally nonnull tenses), the inflectional TAM system includes an inflectional paradigm which can be regarded as 'tenseless' in the sense that it appears to be deficient, if not empty, with respect to temporal (as well as aspectual, see below) functional content. Consequently, works focusing on 'unmarked', 'zero' or 'null' tense, in a morpho-phonological sense (cf. e.g. (Bybee 1990; Tagliamonte \& Poplack 1993; Haspelmath 2021) are also relevant to the present study. Cross-linguistically, however, such morpho-phonologically reduced forms can (but need not) be completely semantically unspecified for temporal and/aspectual content, but even when they are not, they appear to cluster around certain types of meanings, especially presents and aspectually 'light' tense-aspect meanings. The Anindilyakwa zero tense seems to be of the functionally deficient kind, as we examine further below.

Both 'tenseless' languages, and languages with optional tense marking and functionally deficient 'zero tense' (Smith, Perkins \& Fernald 2007; Carolan 2015) are much alike in that they must both resort to temporal and/or aspectual information derivable from the compositional semantics of an utterance, plus discourse contextual information, in order to ascribe a temporal content to tenseless, or 'null tense', utterances. In what follows, we argue that discourse structural (e.g. discourse relations, in the sense of the SDRT framework (Asher \& Lascarides 2003)) parameters also play a key role in order to achieve an appropriate temporal interpretation. This is in line with important results garnered in the 1990's and 2000's about the interplay between aspectuo-temporal meanings and discourse structure, notably through SDRT based-analyses (following notably (Lascarides \& Asher 1993a; Lascarides \& Asher 1993b; Lascarides \& Oberlander 1993)see (Caudal 2012) for a more recent instantiation of such an approach).

Of course, temporally unspecific 'zero tense' forms differ from simple aspectually underspecified tenses, demonstrated for instance by (Smith 1991) notion of (aspectually) neutral tenses, (Nash 2017) notion of structural deficiency, or (again) the lack of 'aspectual functional substance' à la (Ritter \& Wiltschko 2014). As we will see in Anindilyakwa, however, this language offers a phonologically reduced paradigm which is at once temporally and aspectually underspecified, suggesting that a verb form can be at once lacking with respect to both temporal and aspectual functional content.

\subsection{The Anindilyakwa language and its TAM system}

Anindilyakwa is a non-Pama-Nyungan language, spoken by over 1,400 people living on the Groote Eylandt archipelago, in the NT, Australia (Department of Infrastructure, Transport, Regional Development and Communications, Australian Institute of Aboriginal and Torres Strait Islander Studies \& Australian National University 2020). In the context of Australian Aboriginal languages, it is a fairly vibrant language, and one of the few that is still being acquired by children. 


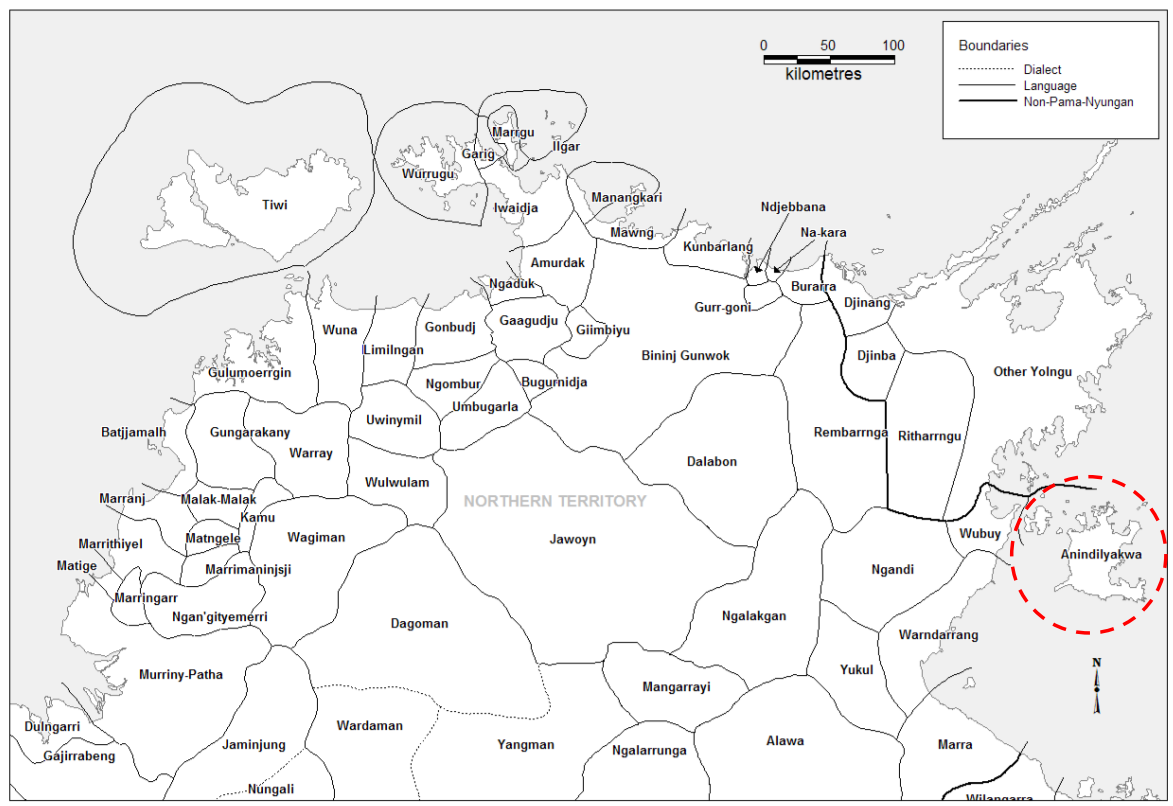

Figure 1. Anindilyakwa and surrounding Top End languages (Harvey 2008)

Like many languages of northern Australia, Anindilyakwa is richly polysynthetic and morphologically complex. Its TAM paradigms are no exception to this, as they are realized through discontinuous morphs (Carroll 2016) involving a portmanteau prefix (combining pronominal+TAM information) and a TAM suffix (Bednall 2020: 26). In spite of its many TAM paradigms, the language is strikingly underspecified for aspect: it possesses two aspectually 'neutral' indicative paradigms, namely a 'neutral' past tense paradigm (REAL-V-PST, cf. (1)), plus a temporally and aspectually underspecified TAM paradigm, with a phonologically null suffix exponent $(R E A L-V-\varnothing$, cf. (2)). Note that departing from (Bednall 2020), and following (Caudal, Mailhammer \& Bednall 2019), we are analyzing each combination of prefix and suffix exponents as a single discontinuous TAM morph, i.e. as instance of so-called 'distributed exponence' in the sense of (Carroll 2016).

$\begin{array}{lll}\text { kembirra } & \text { nom-awiyebe- } \boldsymbol{n} \boldsymbol{\boldsymbol { }}=\text { ma } & \text { mamawura } \\ \text { then } & \text { REAL.VEG-enter-PST=SType } & \text { VEG.sun }\end{array}$

'Then the sun set'

VEG.sun

(Morungkurra Text, 28-9)

(2)

$\begin{array}{ll}\begin{array}{l}\text { yarrungkwan-akan } \quad \text { nenangkwarrba } \\ \text { yesterday } 3 \mathrm{~m} \text {-that } \quad 3 \mathrm{~m} . \mathrm{man} \text {-akbarranga- } \emptyset=m a \\ \text { mijiyelya }\end{array} & \text { REAL.3m>VEG-find-USP=SType } \\ \text { VEG.beach } & \\ \text { 'Yesterday he found the beach' } & \\ \text { (JL, JRB1-018-01, 00.05.31) } & \end{array}$

Note that in addition to $R E A L-V-\varnothing$ and $R E A L-V-P S T$ mentioned above, there are eight other discontinuous TAM morphs (portmanteau prefixes + TAM suffixes) in the verbal inflectional TAM system (REAL-V-NPST, IRR-V-NPST, IRR-V-PST, IRR-V-, , IRR-V$P O T, D E O N-V-N P S T, D E O N-V-\varnothing, D E O N-V-P O T)$. This paper, however, focuses principally on the temporally and aspectually underspecified $R E A L-V-\varnothing$ paradigm (see Bednall 2020 chpts 6 and 9, for discussion of other TAM paradigms). 


\subsection{Our research question and existing analyses}

The starting point for the present study is Bednall's (2020) account of the zero inflection. On the surface, the temporal anchoring of REAL-V- $\varnothing$ utterances appears to be largely determined by the Aktionsart of the verb: stative verbs seem to favor a present anchoring, verbs describing atomic telic events (cf. Dowty 1986; i.e. achievements) impose a past interpretation, while verbs describing either atelic dynamic events (i.e. activities and unbounded changes-of-state events) or accomplishments are capable of both readings, as displayed in Table 1.

Table 1. Temporal properties of REAL-V-Ø marking, as described in (Bednall 2020: 219)

\begin{tabular}{cccc}
\hline Temporal anchoring & States & Activites + Accomplishments & Achievements \\
\hline Past & $\times$ & $\checkmark$ & $\checkmark$ \\
Present & $\checkmark$ & $\checkmark$ & $\times$ \\
\hline
\end{tabular}

This leads to the following principles that (Bednall 2020: 222) posits (based on similar principles of (Smith \& Erbaugh 2005; Smith, Perkins \& Fernald 2007)), where atomic events (Dowty 1986; Caudal 1999) correspond to non-scalar/non-incremental telic events (i.e. more or less to achievements, see (Caudal \& Nicolas 2005) for more on this).

1. The Deictic Principle: Situations are located with respect to Speech Time (Smith et al 2007: 44);

2. The Simplicity Principle of Interpretation: Choose the interpretation that requires the least information added or implied (Smith et al 2007: 60);

3. The Temporal Schema Principle: Interpret zero-marked clauses according to the temporal schema of the situation (Smith et al 2007: 61).

a. Stativity Constraint: stative events are not located in the past.

b. Atomic Constraint: atomic events are not located in the present.

It should be noted that Table 1, and the above principles, deviate somewhat from some typological work that has been conducted looking into functionally deficient tenses, with known temporal effects of aspectual meanings regarding functionally deficient tenses, or tenseless languages. Thus, according to the so-called 'present perfective paradox' (Malchukov 2009; De Wit 2016), aspectuo-temporally/deficient unspecified verb forms should trigger a non-present reading with all telic/bounded and dynamic utterances, vs. a present reading with stative utterances. However, in Anindilyakwa, not only can activity and accomplishment verbs anchor to either the present or the past, morphologically stative verb forms marked with the so-called INCHoative suffix (i.e. that give rise to stative, stative-resultative/perfect, or change-of-state/perfective readings depending on contextual parameters, similar to other Australian languages such as Panyjima (Caudal, Dench \& Roussarie 2012)) can also vary in their temporal anchoring, as in (3)-(4).

(3) yirra-rrangka- $\varnothing=m a$ arakba ngayuwa

REAL.2A-see-PST=STYPE

COMPL.ACT

1.PRO

nong-enibu-dho- $\varnothing=m a$

REAL.1-alive-INCH-USP=STYPE

'Now you have seen that I really am alive again...'

(Bednall 2020: 62)

(4) $\boldsymbol{n}$-eniba-dho- $\emptyset=m a$

REAL.3m-alive-INCH-USP $=$ STYPE

'He came back to life'

(Bednall 2020: 149) 
Other typological works seem to be partly in agreement with Bednall's (2020) generalizations (see e.g. (Bybee 1990: 12-13), which observes that dynamic predicates, regardless of their telicity, can give rise to past temporal anchorings in at least some languages, in contrast with stative, whose 'default interpretation' seems to be past (the latter claim being at odds with Bednall's generalization in Anindilyakwa, while the former is not).

These divergences are indicative that further research on the aspectuo-temporal interpretation of 'temporally deficient' forms in general, and the Anindilyakwa $R E A L-V-\varnothing$ paradigm in particular, is necessary. The remainder of this paper will precisely address this issue, by examining which of the above generalizations and principles hold by testing them against a rigorous quantitative assessment.

\section{Materials and Methods}

The present study was conducted on a sub-set of a corpus of roughly 100,000 words (well over 10,000 utterances, in the context of a polysynthetic language), comprising 55 hours of elicitation material, dialogues and narratives, plus other collected narratives. The sub-set used for this study is roughly one quarter of the total corpus: roughly 25,000 words.

The three main types of material making up our corpus specifically involve the following types of data:

- Elicited utterances, either through traditional questionnaires (especially as translation tasks), meta-linguistic elicitation material (e.g. morphological flash cards), or experimental elicitation based on the Event Description Elicitation Database (EDED, cf. (Mailhammer \& Caudal 2019); see details below, and Caudal \& Mailhammer (this volume) for further details);

- Oral narratives recorded in 2016-19, as well as a collation of legacy narrative recordings (1970s-90s);

- A (partial) translation of the Bible (1992): Neningikarrawara-angwa Ayakwa.

A precise break-down of our corpus according to the above data types is given in table 2 .

Table 2. Break-down of our corpus according to data type (genre)

\begin{tabular}{lrr}
\hline Data type & Audio duration & Word count \\
\hline Elicited data (translation tasks; & & \\
stimuli-prompts) & 15h16min25sec & 19,906 \\
Spoken narratives & 01h04min46sec & 3789 \\
Translated text (Bible) & - & 699 \\
TOTAL & 16h21min11sec & 24,394 \\
\hline
\end{tabular}

\subsection{Annotation scheme}

We extracted all indicative uses of the zero inflection from these various sources, and proceeded to annotate them so as to identify the role possibly played by various parameters in saturating their temporal and aspectual meanings. Our annotation scheme thus involved some usual and obvious culprits (telicity vs. atelicity/non-telicity, dynamicity vs. stativity, atomicity vs. non-atomicity (in the sense of (Dowty 1986; Caudal \& Nicolas 2005). In addition, we randomly extracted a number of overt past and non-past (i.e., present) marked verbs, to establish a base-line for our experiments.

Our annotated corpus and quantitative measurements (plus some figures) are available at the following address: https://cloud.llf-paris.fr/nextcloud/s/yHNeLig7Bnf42by. It comprises exactly 214 occurrences of zero-inflected verbs, 101 occurrences of past-marked 
verbs, and 22 occurrences of non-past-marked (= present-marked) verbs. A systematic annotation of these occurrences was undertaken, with the following attributes and values:

- Verb root

- Verb translation

- $\quad$ Aktionsart = \{state; neg(ative) state; inchoative state (CofS); activity; iterated actitivity; bounded activity; bounded iterated activity; inchoative activity; unbounded change-of-state; achievement; iterated achievement; bounded iteration of achievement; hab(itual) achievement; accomplishment; iterated accomplishment; hab(itual) accomplishment; semelfactive; iterated semelfactive\}

- Complexity = \{CUMulative; AToMic; PLURactional ACHievement BounDED; ATM GROUP (group of atomic events constituting a non-scalar, complex atom); ATM PREP (atomic event with a preparatory stage); INCH ATM (atomic inchoative event) ; STATE HABitual; BD CUM (bounded cumulative); BD CUM MAX (maximized cumulative event, via some overt quantifier); Q INCR (quantity incrementality - i.e. event involves an incremental theme/patient argument), $S$ INCR (quality incrementality - event is telic and scalar but does not involve an incremental theme/patient argument) (Caudal \& Nicolas 2005); PLUR ACT (pluractional activity); PLUR ACT MAX (maximized pluractional activity); PLUR ACH (pluractional achievement); PLUR ACC (pluractional accomplishment); PLUR ACH BD (bounded pluractional achievement); PLUR ACC BD (bounded pluractional accomplishment); HAB ACH (habitual achievement); HAB ACC (habitual accomplishment); SEMELFactive; SEM BD (bounded semelfactive)\}

- $\quad$ Scalarity $=\{n($ on scalar); $b$ (inary scale); open scale; closed max(imal scale); dna (does not apply)\}

- $\quad$ Control(ling subject $)=\{\mathrm{y}(\mathrm{es}) ; \mathrm{n}(\mathrm{o})\}$

- Viewpoint aspect=\{IMPFV (imperfective); PFV (perfective); PERF (perfect); PFVWeak (weak perfective)\} (where 'weak perfective' correspond to non-culminating readings of telic utterances, cf. (Martin 2019))

- Overt present marking in complex clause / clause chain $=\{x=$ unspecified; $m=$ present modifier: $\mathrm{i}=$ inflectional present marking\}

- Overt past marking in complex clause / clause chain $=\{x=$ unspecified; $m=$ past modifier: $t=$ past tense marking; $t \gg$ past tense marking of matrix clause $\}$

- $\quad$ Aspect quantifier $=\{\mathrm{x}=$ unspecified; $\mathrm{d}=$ durative modifier $; \mathrm{i}=$ iteration marker or context ; $r=$ reduplication; $1=$ lengthening intonation with durative meaning, especially in the sense of (Mailhammer \& Caudal 2019); $h=$ habitual context or marker\}

- Temporal succession $=\{\mathrm{c}=$ connective; $\mathrm{x}=$ unspecified; it $=$ iteration with micro succession; $11 \mathrm{l}=$ linear lengthening; cons = construction imposes temporal succession; $p=$ parataxis with sequence of events $; g=$ generic context (no temporal succession; :: = durative lengthening; $\mathrm{o}=$ (temporal) overlap)

- Structural context (discourse relation introducing relevant utterance into context) $=\{$ Narration; Background; Back(ground) Fore(ground) (BackgroundForward, cf. (Asher, Prévot \& Vieu 2007)); Fore(ground) Back(ground) (= BackgroundBackward, ibid.)

- $\quad$ Example temporal reading $=\{$ past; present $\}$

- $\quad$ TA context $=\{\mathrm{SoE}=$ sequence of events; PstMod $=$ past modifier; AspMod $=$ aspectual modifier $;$ EpistMod $=$ Epistemic Modifier $;$ PerfMod $=$ perfect modifier; DiscCon $=$ discourse connective; $-\mathrm{PST}=$ past inflection; $-\varnothing=$ zero inflection; $-\mathrm{PR}$ $=$ present inflection; - IRR.PST $=$ past irrealis inflection; Overlap $=$ temporal overlap; TempShift = temporal shift context; XTD = durative lengthening (especially linear lengthening intonation; RED $=$ morphological reduplication ; RED-echo $=$ full (word) reduplication; $\mathrm{V}=$ verb; Iter $=$ iteractive predicate $; \mathrm{Hab}=$ habitual marker/context; Rel $=$ relative clause $; \mathrm{X} \gg \mathrm{Y}=$ matrix $\mathrm{X}$ dominates $\mathrm{Y}\}$ 
- Overt TA pattern $=\{\mathrm{V} 1-\varnothing:$ relevant annotated verb (with zero inflection) $; \mathrm{V}-3 /-$ $\mathrm{V}-2 / \mathrm{V}-1 / \mathrm{V} 0-$ : verbs preceding annotated verb $; \mathrm{V}+1 / \mathrm{V}+2+\mathrm{V}+3+\mathrm{V}+4=$ verbs following annotated verb; IRR.PST = past irrealis ; PST = past $; \mathrm{PR}=$ present; $:::=$ durative lengthening\}

- Notes

- Example in Anindilyakwa

- Example gloss

- Example translation event predicates.

Complexity refers to the broad aspectual complexity attached to a particular type of event descriptions, in relation to subevent structure and event quantification. It crucially distinguishes bounded vs. unbounded atelic events, quantity vs. quality incrementality (i.e. whether or not an incremental, scalar reading gets projected onto the internal structure of some theme/patient argument), pluractional vs. singular event descriptions (whether atelic or telic/bounded - this comprises what we have dubbed 'atomic groups', which though plural at some abstract level, effectively form a single atomic event; the term was coined after theories of nominal reference à la Link/Landman (see e.g. (Landman 1989b; Landman 1989a). Maximized readings (i.e. bounded readings arising from a limited duration adverbial) were also distinguished from simple bounded readings here, as they also involve different contextual parameters.

Determining boundedness, sequence-of-event contexts, and often, aspectual viewpoint meaning, was largely effected using discourse structural information, i.e. by trying to identify the exact rhetorical relation (Asher \& Lascarides 2003) attaching the relevant zero-marked discourse referent to the current discourse context, at the relevant attachment site (generally the previous or following discourse referent (and verb form) depending on discourse relations). Such a methodology is not novel, and has already proven useful when ascertaining aspectual viewpoint meaning for aspectually and or temporally underspecified tenses (see e.g. (Caudal \& Ritz 2012; Caudal 2015). By and large, this is based on (i) the well-known observation that certain discourse relations require temporal overlap between events (e.g. Background), while others impose temporal succession (e.g. Narration, or Result) and (ii) the theoretical generalization that tenses denote rhetorical functions, i.e. that aspectual viewpoint is tightly connected with rhetorical structure (Caudal \& Roussarie 2005; Caudal 2022).

\subsection{Some preliminary observations and empirical generalizations}

According to Table 1, two event structure classes give rise to categoric interpretative effects: (i) atomic event predicates can only ever give rise to past temporal interpretations of REAL-V- $\varnothing$ utterances (Bednall's (2020) Principle \#3b) while (ii) stative event predicates only ever give rise to present temporal interpretations for REAL-V-Ø ((Bednall's (2020) Principle \#3b)). While our corpus study seems to validate (i)/Principle \#3b, as 84 out of 84 instances of utterances describing telic atomic events (i.e. achievements) are anchored in the past, it invalidates (ii)/Principle \#3a, as 15 out of 27 stative utterances are anchored in the past without said past events being inchoatively re-interpreted; in other words, they denote bona fide states, not coerced change-of-state events.

In some cases, it was somewhat difficult to ascertain whether an accomplishment vs. some kind of activity reading should prevail. Even more tellingly, especially in cases of elicited iterative or habitual uses, it was difficult to determine whether a bounded / perfective or unbounded / imperfective of pluractional / iterated or habitual event should prevail. Thus, while the translation of (5) suggests a perfective iterative reading, that of (6) is extremely unclear as to the exact aspectual interpretation of the sequence. 
(5) angkawura angkwababarna no-lhoka-Ø en=lhang=wa 329

one.day always REAL.3m-go-USP 3m.PRO=POSS=ALL 330

angalya

NEUT.place

'he went to his house several times'

(JL, JRB1-049-01, 00.09.25-00.09.34)

(6) arakbawiya angkababarnama nə-lhaka-Ø

en $=$ lhang $=w a$

long.ago always

REAL.3m-go-USP

$3 \mathrm{~m} \cdot \mathrm{PRO}=\mathrm{POSS}=\mathrm{ALL}$

angalya

NEUT.place

'like several times, many times, or several times he used to- went- walked to his house' [speaker translation]

(JL, JRB1-049-01, 00.13.00-00.13.20)

Event structure classes are represented as indicated in Table 3, with achievement describing utterances being by far the most common event description type in our corpus (with almost $43 \%$ of all zero-marked utterances); change-of-state utterances even reach a staggering $76 \%$ dominance of zero-marked utterances.

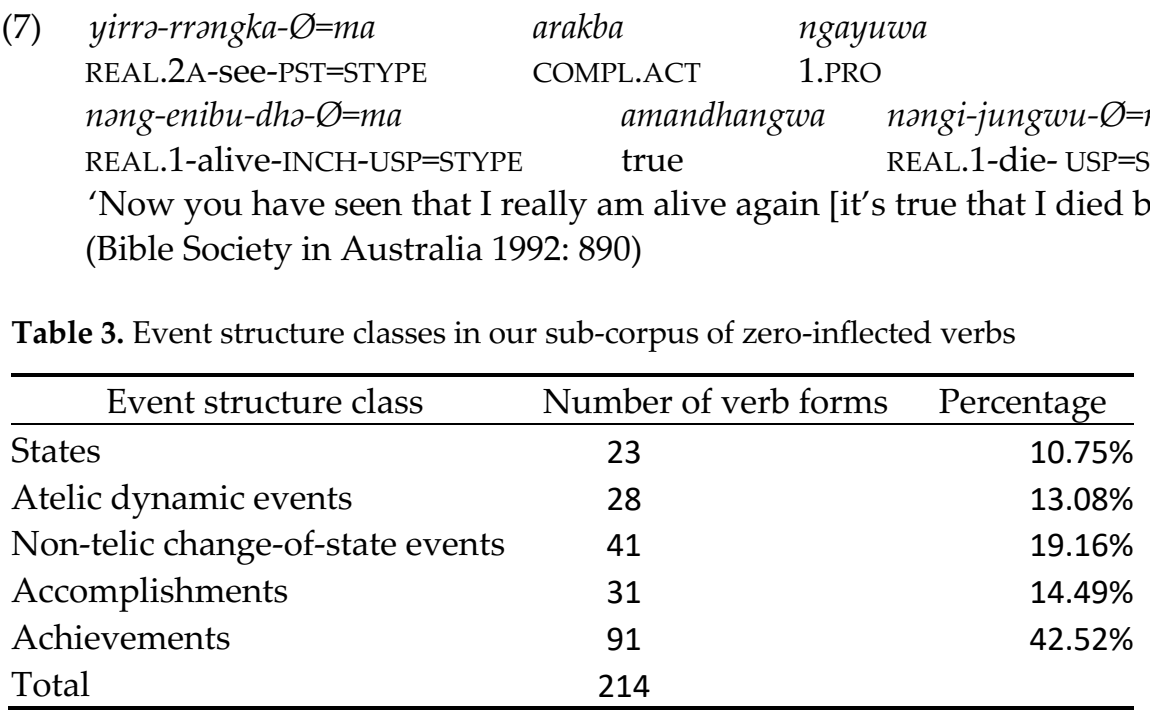

Figure 2 below offers a visual rendering of table 2, revealing that telic utterances are very predominant in the sample. 


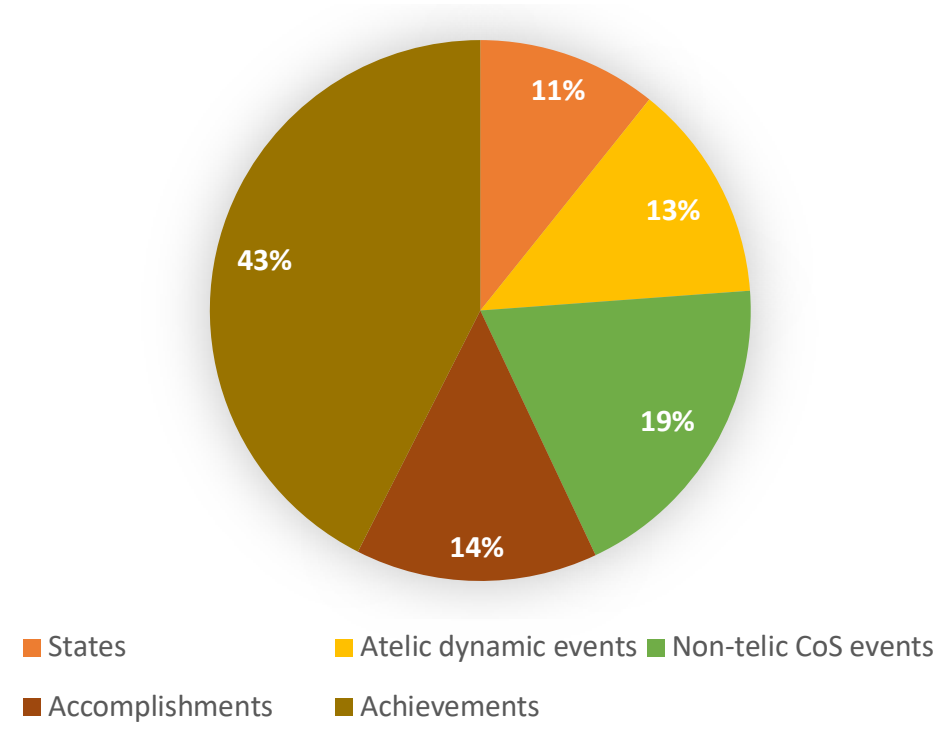

Figure 2. Event structure composition of our zero-inflected corpus

This suggests a strong bias between zero-marking towards change-of-state meanings, as event structure classes in other tenses (e.g., the simple past tense) do not exhibit such a stark bias towards change-of-state descriptions, as shown in tables 4 and 5 . Table 5 reveals that our non-past sub-corpus only comprises atelic verbs denoting cumulative, unbounded event types. Verbs lexically describing achievements do appear, but must receive coerced durative, prospective/proximative (8) or hortative/volitional modal readings, or are coerced into scalar 'degree achievement' descriptions (9) (in effect, these surface an unbounded change-of-state predicates, i.e., as atelic dynamic event predicates).

(8) ngumu-ngwanja-ja-na=ma

REAL.1>VEG-stop-CAUS-NPST=STYPE

'I'm stopping the car'. (JL, JRB1-018-01, 00.15.37-00.15.42)

(9)

ambaka+lhangwa na-mənəngka-dhə-nə=ma

slowly REAL.NEUT-different-INCH-PST=STYPE

ena

(durative/prospective) angalya

'slowly this place seems to get different' (JL, JRB1-007-01, 00.01.29-00.01.34 narrative)

The latter semantic generalization is in line with well-known observations related to the so-called 'present perfective paradox' (De Wit 2016); said paradox predicts that e.g., utterances describing punctual events cannot receive a present tense marking unless their meaning undergoes some sort of semantic shift (whether aspectual, or aspectuo-modal). While this shows that major event structure composition differences appear in our corpus between past (or mostly past) vs. non-past tense forms, this also indicates that it is not irremediably 'skewed' towards past reference, and the observed differences might reflect on inherent tendencies of tenses, rather than just the textual genre composition of the corpus. Interestingly, Table (4) demonstrates that our overt past sub-corpus and our zero inflection sub-corpus do not have matching event structure compositions, event if they involve a roughly similar proportion of utterances describing non-change-of-state, cumulative, unbounded events (23-26\%). This confirms that event structure composition depend at least in part on tenses, and not merely on textual genre biases. 
Table 4. Event structure classes in our sub-corpus of past-inflected verbs

\begin{tabular}{lcr}
\hline \multicolumn{1}{c}{ Event structure class } & Number of verb forms & Percentage \\
\hline States & 7 & $6,93 \%$ \\
Atelic dynamic events & 21 & $20,79 \%$ \\
Non-telic change-of-state events & 37 & $36,63 \%$ \\
Accomplishments & 6 & $5,94 \%$ \\
Achievements & 30 & $29,70 \%$ \\
Total & 101 & \\
\hline
\end{tabular}

Table 5. Event structure classes in our sub-corpus of non-past-inflected verbs

\begin{tabular}{lcr}
\hline \multicolumn{1}{c}{ Event structure class } & Number of verb forms & Percentage \\
\hline States & 10 & $45,45 \%$ \\
Atelic dynamic events & 12 & $54,55 \%$ \\
Non-telic change-of-state events & 0 & $0,00 \%$ \\
Accomplishments & 0 & $0,00 \%$ \\
Achievements & 0 & $0,00 \%$ \\
Total & 22 & \\
\hline
\end{tabular}

Note that our classification incorporates contextual effects on the construal of event structure, including the impact of e.g. sequence-of-event contexts, inchoative interpretations, etc. 'Non-telic' change-of-state (CoS, henceforth) events incorporate semelfactives, bounded or maximized states, activities or event pluralities, or inchoative states. As zero tense is also aspectually underspecified, these are the only reliable aspectual information we can resort to. Of course, we have tried to determine a viewpoint aspect on the basis of contextual meanings; it effectively boils down to the distinction between CoS event structures (which trigger a perfective-like interpretation) vs. non-CoS event structures (which trigger an imperfective-like interpretation).

One important caveat in our annotation methodology has to do with perfect-like readings of zero-inflected verbs such as in (7). Although they have present relevance in some sense, we have nevertheless classified those as past, since they do locate an event in the past, plus some associated result event in the present, which we take to be 'perfect state' à la Nishiyama \& Koenig (2010). As it is unclear whether such perfect readings are bona fide semanticized readings of zero-inflected realis verbs, or something less semantically 'hard wired' in the spirit of proposals made in, for instance, Caudal (2022) (at the semantic/pragmatics interface in terms of conventional implicatures), we have simply treated instances of perfect-looking uses as being anchored in the past.

\section{Results of a Fisher exact test-based quantitative study}

After annotating our zero sub-corpora as exposed above, we have analyzed the data thus constituted using a quantitative technique well suited to small samples such as our corpus, namely Fisher exact test, or FET. FET helps to determine which of the parameters of the annotation scheme could possibly constrain the temporal anchoring interpretation of zero-inflected Anindilyakwa verbs. Whenever possible, we have also run chi-square tests (but they seem to yield very similar results). As we will see, temporal anchoring and viewpoint are not entirely orthogonal, but certainly distinct, with respect to the parameters they depend on.

To assess correlation between parameters, FET requires the distribution of parameters and correlated values shown in Table 6 . 
Table 6. Positively and negatively correlated parameters and Fischer Exact Test (FET)

\begin{tabular}{|c|c|c|}
\hline \multicolumn{2}{|c|}{} & \multicolumn{2}{|c|}{ Parameter 2} \\
\hline Parameter 1 & Positive value & Negative value (opposite) \\
\hline Positive value & a-positive correlation & c-negative correlation \\
\hline Negative value (opposite) & b-negative correlation & d-positive correlation \\
\hline
\end{tabular}

From Table 3, the computation of FET can yield two measures establishing correlations between parameters - a classic significance measure $p$ (where $p$ needs to be inferior to 0,01 to achieve significance), and an odds ratio, calculated as indicated in (10), and which the magnitude of superior predictability of the positive correlations, when compared to the alternative, negative correlations.

$$
\widehat{O R}=\frac{\frac{a}{b}}{\frac{c}{d}}=\frac{a \cdot d}{b \cdot c}
$$

\subsection{Telicity vs. non-telicity}

Table 7 below was construed to determine whether telicity constituted a determining parameter for past temporal anchoring. It opposes telic and non-telic utterances, where non-telic includes atelic utterances, but also utterances denoting non-telic change-of-state predicates (such as e.g. semelfactive events and inchoative readings of atelic verbs).

Table 7. Telic vs. non-telic verbs and temporal anchoring

\begin{tabular}{cccc}
\hline Event structure opposition & Past & Present & Total \\
\hline Telic & 105 & 9 & 114 \\
non-telic (CUM + COS non telic) & 79 & 21 & 100 \\
Total & 184 & 30 & 214 \\
\hline
\end{tabular}

The following visualization (via R's mosaicplot function) makes it obvious that (i) telic events are vastly predominant in the sample and (ii) that telic utterances are biased towards past anchoring, while non-atelic utterances tend to favor a present anchoring, but that (iii) these are not very strong correlations.

445

\section{Telicity vs. non-telicity}

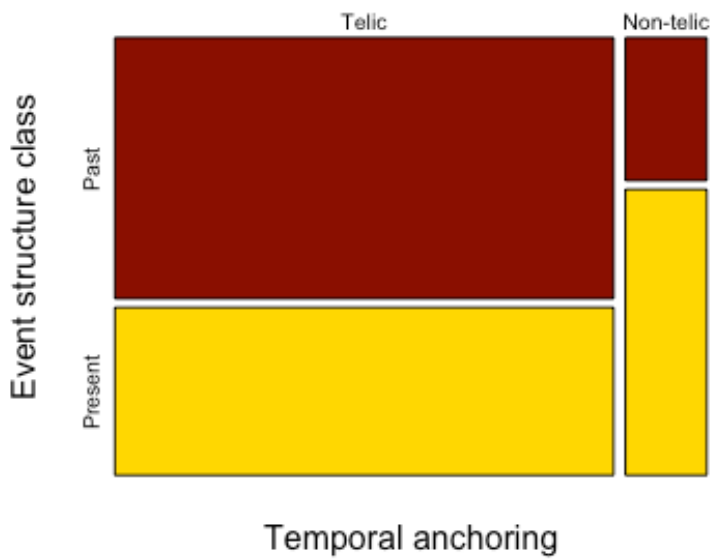

Figure 3. Vizualisation of temporal anchoring of telic vs. non-telic utterances 
Running Fischer exact for our count data ${ }^{1}$, we got a weakly significant p-value 453 of 0.0094196833154142 , and an odds ratio of 3.085, with confidence interval 95\% [1.2714; 8.0887]. A chi-square test yields $X$-squared $=6.8962, \mathrm{df}=1, \mathrm{p}$-value $=0.008638$.

This suggests a marked, but not universal tendency for telic verbs to pair up with a past anchoring, and for non-telic verbs to pair up with a present anchoring - and therefore that telicity/non-telicity cannot be regarded as a truly significant parameter for discriminating present vs. past temporal anchoring. This result is in line with Bednall's (2020) principles.

\subsection{Atomic telic vs. non-atomic telic}

Clearly, this is due to non-atomic telic utterances being capable of receiving a present temporal reading, as shown in table 8 . Running FET on this table ${ }^{2}$ yields a significant $p$ value ( $p=3.2 \mathrm{E}-7)$, and no informative odds ratio, as the data set is too restricted. The positive correlation 'telic non-atomic/present' is fact not warranted, as accomplishment utterances remain most past.

Table 8. Telic atomic vs. telic non-atomic verbs and temporal anchoring

\begin{tabular}{cccc}
\hline Event structure opposition & Past & Present & Total \\
\hline Telic atomic & 91 & 0 & 91 \\
Telic non-atomic & 21 & 10 & 31 \\
Total & 112 & 10 & 122 \\
\hline
\end{tabular}

\subsection{Dynamic vs. stative utterances}

Let us now turn to dynamicity vs. stativity. As non-telic changes-of-state are inherently complex events, and may combine a non-dynamic subevent and dynamic subevent (we argue that this is the case of e.g. inchoative readings of stative verbs, or so-called INCH-derived verbs), we will exclude these in this subsection. This gives us Table 9 below.

Table 9. Dynamic vs. stative verbs and temporal anchoring

\begin{tabular}{cccc}
\hline Event structure opposition & Past & Present & Total \\
\hline Dynamic & 131 & 19 & 150 \\
Stative & 12 & 11 & 23 \\
Total & 143 & 30 & 173 \\
\hline
\end{tabular}

Running FET on this table ${ }^{3}$ yields a significant $p$-value $(p=0.0002412)$, and an odds ratio of 6.220913 (confidence interval at $95 \%[2.1625 ; 18.0003]$ ).

What if we compare stative and dynamic atelic utterances? Table 10 shows that their respective spread converges a lot more. If we run FET on such a table, ${ }^{4}$ we get a nonsignificant $\mathrm{p}=0.38765$, and an odds ratio of 1.9098 , with $95 \%$ confidence interval [0.5361 ; 7.0437].

\footnotetext{
1 The corresponding $R$ command is fisher.test (matrix $(c(112,10,72,20), 2,2$, byrow=TRUE)).

2 In R, fisher.test(matrix $(c(91,0,21,10), 2,2$, byrow=TRUE))

3 In R, fisher.test(matrix (c(131,19,12,11),2,2, byrow=TRUE))

${ }^{4}$ In R, fisher.test(matrix $(c(19,9,12,11), 2,2$, byrow=TRUE))
} 
Table 10. Dynamic vs. stative verbs and temporal anchoring

\begin{tabular}{cccc}
\hline Event structure opposition & Past & Present & Total \\
\hline Dynamic atelic & 19 & 9 & 19 \\
Stative & 12 & 11 & 23 \\
Total & 30 & 30 & 42 \\
\hline
\end{tabular}

Thus, it seems that if we restrict dynamic utterances to their atelic subset, the stative/dynamic opposition ceases to be quantitatively significant. However, this might be in part due to the size of our corpus. As it primarily consists of materials (formal or semiformal narratives, plus elicitation of past event descriptions) involving predominantly past contexts, our corpus is to some extent biased against both stative and dynamic atelic utterances as it favors past or potentially past tenses. Obviously, settling such questions would requires further investigations on a more extended corpus; we will say more on this below in the discussion.

But what really matters is that though neither stative nor dynamic atelic utterances are categorically associated with past or present anchoring, dynamic atelic verbs show a mild preference for past anchoring (this is partly in line with Bybee's (1990) proposal, partly not in line with it), while statives appear to have no inherent tendency at all (pace Bednall's $(2020,2021)$ proposals). neutral. For both event types though, additional contextual information or overt markers always take precedence in terms of temporal anchoring.

\subsection{CUMulative utterances vs. CoS utterances / perfective vs. imperfective-viewpoint utterances}

Since neither telicity nor dynamicity are very good predictors for the temporal anchoring of zero-marked utterances in our corpus, let us now turn to a last possible parameter, namely a basic opposition between utterances describing unbounded cumulative utterances (in effect associated with an imperfective viewpoint reading, by and large), and utterances describing $\mathrm{CoS}$ events in the largest possible sense, i.e. including bounded/maximized readings of atelic events (in effect; all the utterances associated with a perfective viewpoint reading). This gives us table 11 .

Table 11. CUM vs. CoS utterances (or imperfective vs. perfective utterances)

\begin{tabular}{cccc}
\hline Event structure opposition & Past & Present & Total \\
\hline CoS & 153 & 10 & 163 \\
CUM & 31 & 20 & 51 \\
Total & 184 & 30 & 214 \\
\hline
\end{tabular}

The visualization obtained with mosaicplot (figure 4) already reveals a much better predictor than telicity (cf. Figure 3 above). 


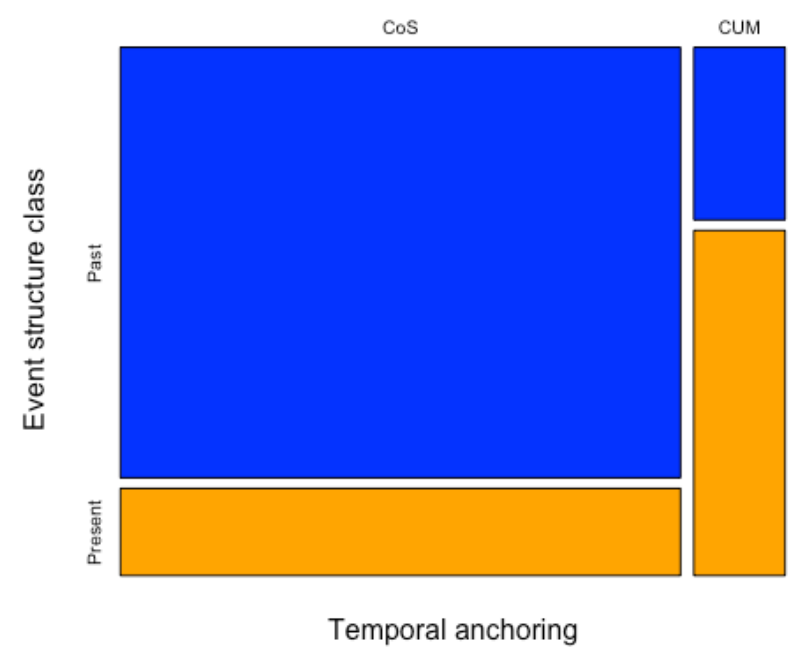

Figure 4. Vizualisation of temporal anchoring of CoS vs. CUM utterances

This is confirmed when we run FET on table $8^{5}$, as we get a very significant $p$-value of 6.4554400236716E-8 and an odds Ratio of 9.7205 (with a 95\% confident interval [3.9072; 25.7194]) - i.e., FET demonstrates that CoS is a much better predictor than telicity. Although not a categorical parameter, this suggests a very strong tendency for CoS utterances to be anchored in the past. As we have seen above, CoS utterances correspond more or less to a perfective viewpoint reading, while CUM utterances associate with an imperfective viewpoint reading.

\section{Discussion}

Let us turn now to a detailed discussion of the above results, trying to determine to what extent they are meaningful and tell us key novel things concerning parameters constraining the interpretation of zero-marked utterances, in addition to what extent they might have a potentially broad typological significance.

\subsection{Possible biases due to discourse/textual genres?}

Before assessing the positive contribution of our results, we also need to frame their significance with respect to the nature of the data used here, so as to circumvent, or at least understand, possible biases. Our corpus does not incorporate dialogical data per se, only semi-formal/conversational narratives with a dialogical dimension, on top of formal narratives and elicited data (mostly with prompts towards a past temporal anchoring, what's more). This might be detrimental to the representativity of present temporal anchorings with zero-marked utterances in our corpus. But vice versa, it might also be the case that zero-marked utterances are infrequent in dialogue, and mostly found in narratives. As dialogical material is de facto under-represented in the data collected so far in the languages, it is impossible at this stage to address this potential concern; additional substantial fieldwork will be required to be able to assess whether or not our corpus introduces an unwanted bias in the experiment.

The concern is genuine, in the sense that certain aspectual meanings (perfective, change-of-state events) are intuitively more common in narrative, than in dialogue. The same holds true of temporal-succession discourse relations (rhetorical relations associated with perfective, sequence-of-events contexts are prevalent in narratives, especially 'formal' narratives (myths, legends, see e.g. Carruthers 2005; Caudal 2010) - and the latter are predominant in the narrative part of our corpus. We should ideally be able to conduct

5 fisher.test(matrix $(c(153,10,31,20), 2,2$, byrow=TRUE) $)$ 
separate quantitative pilot studies on genre-specific corpora, and compare the results, to fully validate the conclusions of the present study. Obviously, this must be left to future developments.

\subsection{Novel empirical generalizations for the grammar of Anindilyakwa?}

With the above caveat in mind, what can we reasonably say about our results? Even if present readings for zero tense are under-represented in our corpus, past readings are not, and it seems rather unlikely that the significance of the various parameters here used will be greatly impacted. A larger proportion of present anchorings will most likely only improve overall significance in the above results. What they can potentially change, therefore, is to grant dynamicity and telicity a better significance than they currently have. However, by the same token, that of the CoS/CUM opposition will also be improved. So that we are confident in the ranking of parameters given below in Table 9 already constitutes a reliable result.

Table 12. Summary of quantitative findings, and ranking of parameters for temporal anchoring

\begin{tabular}{cllc}
\hline Parameter & \multicolumn{1}{c}{ Significance $(\mathrm{p})$} & Odds ratio & Ranking \\
\hline Telic/non-telic & 0.0094196833154142 & 3.085 & 3 \\
Dynamic/non-dynamic & 0.0002412 & 6.220913 & 2 \\
CoS/non-CoS & $6.4554400236716 \mathrm{E}-8$ & 9.7205 & 1 \\
\hline
\end{tabular}

As we have seen above, while telicity itself is not a good predictor, atomic telicity is the only event-structure based information constituting a categorical predictor in our corpus: all atomic telic events were anchored in the past. This validates Bednall's (2020) Principle \#3b ('the Atomic Constraint').

In contrast, and contrary to Bednall's (2020) Principle \#3a ('the Stative Constraint'), stativity is not a categorical predictor according to our data, and does not even seem to have an inherent temporal anchoring tendency. This causes the dynamic/stative opposition to be a mediocre predictor for temporal meaning: while dynamic atelic events have a slight tendency to induce past readings (this is a toned-down version of Bybee's (1990) original claim), this is mitigated by the more neutral temporal profile of stative events, and causes the stative/dynamic atelic event opposition to be unable to rival the significance of the CUM/CoS opposition as a temporal predictor.

In addition to telic atomic utterances, it seems that non-telic CoSs such as e.g. inchoative readings of stative verbs, single-event semelfactives and INCH-derived verbs can only receive a past temporal anchoring as well. This suggests that atomic CoSs, and not just telic atomic events, have a categorical effect on temporal anchoring - this is a slight inflection to Bednall's (2020) 'Atomic Constraint', which places more emphasis on atomic telic events.

To put it in a nutshell, there is a sharp asymmetry in the manner in which aspectual constraints are organized with respect to the temporal anchoring of zero-inflected Anindilyakwa verbs:

- Only atomic CoS events (whether telic or not) categorically determine (past) temporal anchoring, and cannot be overruled or modified by any additional information or overt temporal marker

- The temporal anchoring of all other event structure types can have both present and past temporal anchorings in our corpus. And even when an event structure type is inherently biased towards a particular anchoring (i.e., the past in the case of atelic dynamic events), such biases are always overruled by additional contextual temporal information and/or overt temporal marking - through overt past vs. present adverbials, or when a temporally explicit inflection marks another verb they are temporally related to via e.g. Narration or Background (i.e., when they are part of a single discourse topic; this is a very important discourse 
contextual factor in the semantics and pragmatics of tenses (see Caudal (2022) for a detailed discussion of this question $)^{6}$.

We would like to highlight in the latter regard the key role played by discourse structural parameters and viewpoint in our study: the main shedding line between past vs. present anchoring as determined by aspectual content, is very much the change-ofstate/perfective vs. non-change-of-state/imperfective reading distinction. Our analysis clearly departs from past investigations on aspectual parameters governing the contextual interpretation of aspectuo-temporally deficient tenses, in that we stress the importance of an overall aspectual interpretation, incorporating not only event structure parameters, but also discourse structurally determined aspectual meanings.

\subsection{More on empty vs. non-empty contexts / overt temporal marking}

As we have just seen, it seems that not all event structure classes exhibit the same 'natural tendencies' according to our results: thus, accomplishment utterances tend to be more frequently past than say states, whereas (unbounded) atelic dynamic utterances pretty stand in the middle. However, it is difficult to assess whether or not these tendencies are general, or a simple artifact of the nature of our corpus, as suggested in $\S 4.1$, as it is probably skewed towards temporally past contexts, and thus probably adds to the observed temporal anchorings, and the frequency of event structures.

But there is one move we can, and should make, in order to mitigate this uncertainty, namely try and measure the effect of 'temporally empty contexts' on the effects of CoS vs. CUM utterances. Such empty contexts cropped up mostly in our elicited material, when no temporal prompt had been given to informants. Table 10 gives the figures for the CoS vs. CUM opposition in a temporally empty context.

Running FET on Table 10,7 we get a more significant $p$-value than in all contexts ( $p=1.5262396732922 \mathrm{E}-8)$, and a much higher odds ratio (18.7066), with a 95\% confidence interval $[5.724 ; 69.8122]$. This seems to vindicate the hypothesis made above, that in nontemporally skewed contexts, greater significance would be achieved for aspectual parameters - i.e. in the absence of overt and/or covert temporal contextual information, 'aspectual tendencies' are free to assert themselves. This also gives strong backing to the idea that context - especially discourse structure, we believe - plays an essential role in the temporal interpretation of zero-tensed verbs in Anindilyakwa.

Table 13. Temporal anchoring of CUM vs. CoS utterances in an empty context

\begin{tabular}{cccc}
\hline Event structure in empty context & Past & Present & Total \\
\hline CoS & 65 & 7 & 72 \\
CUM & 9 & 19 & 28 \\
Total & 74 & 26 & 100 \\
\hline
\end{tabular}

\subsection{Typological consequences}

The present results have potentially far-reaching typological consequences. They clearly demonstrate the need for combining detailed semantic annotation with quantitative analyzes in order to rigorously assess the impact of the most relevant factors in the interpretation of aspectuo-temporally deficient tenses. Empirical generalizations based on simple counts and crude semantic categories such as e.g., the Vendler-classes style aspectual characterizations, are obviously too coarse-grained a method to frame the

${ }^{6}$ This clearly realtes to an intuition underlying (Bybee 1990)'s old observation about statives: their present temporal anchoring is only a default reading, i.e. it seems to crop up in temporally 'empty' contexts.

7 fisher.test(matrix $(c(65,7,9,19), 2,2$, byrow $=$ TRUE $))$ 
interpretative intricacies underlying semantically deficient forms. Context sensitivity, event complexity, and non-Vendlerian parameters such as viewpoint-like meanings, are key to unravelling the mysteries lurking behind such forms.

Interestingly, our results seem to connected with the so-called '(present) perfective paradox' (Malchukov 2009; De Wit 2016), in that they establish a connection between CoS/perfective meanings and pastness, vs. CUM/imperfective meanings and presentness. A lot more could be said about this, but obviously, this must be left to future research.

\subsection{Comparative observations}

Before closing the discussion, we would like to highlight the fact that the Anindilyakwa aspectuo-temporally underspecified 'zero' tense is not an isolated phenomenon among Australian languages. Similar underspecified tenses been described for a number of Australian languages, see for instance the so-called 'non-future' inflection in MurrinhPatha (Nordlinger \& Caudal 2012), as shown in (11)-(14).

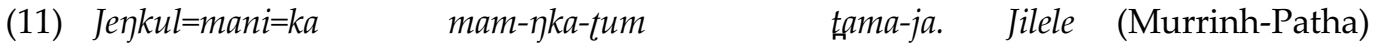
[name] =attempt=cst do.3sg.nfut-eye.appl-dry say.2sg.irr father 'how about Yengkul, the one who stirs up dust in his truck, who you call father?' (Mansfield 2020: 5)

(12) wurran-nintha-lili (Murrinh-Patha)

they.6.PRES-du/m-walk

3sgS.go(6).nfut-du.m-walk

'They are walking.'

((Street 1996: 208) in (Nordlinger \& Caudal 2012: 83))

(13) mam-purl

(Murrinh-Patha)

I.8.PERF-wash

'I washed it.' ((Street 1996: 209) in (Nordlinger \& Caudal 2012: 83))

(14) bayam-lele-dim ku-weye ku-put ikat $=t e$

(Murrinh-Patha)

affect.3sg.nfut-bite-sit.impf

'the cat is biting the dog'

anim-dog anim-cat=agent

(Mansfield 2020: 4)

Interestingly, Nordlinger \& Caudal argue that event structure classes seem to determine the temporal anchoring of non-future utterances in Murrin-Patha (with telic utterances being anchored in the past, vs. atelic utterances being anchored in the present), very much in line with initial observations made in (Bednall 2020).

One should also mention the so-called 'actual' tense in Kayardild, described in (Evans 1995; Round 2013) as a the 'default', morphologically minimal tense. The actual inflection appears to be both temporally and aspectually deficient, cf. (15)-(16), and contrasts with an aspectually underspecified past tense. Unlike the Murrinh-Patha past tense system, the Kayardild past tense system is therefore very similar to the Anindilyakwa tense system. Moreover, and contrary to (Nordlinger \& Caudal 2012)'s Vendlerian approach, Evans claims that temporal modifiers are used to specify the temporal anchoring associated with actual-marked utterances; the latter hypothesis is of course rather reminiscent of our findings concerning certain event structure classes in Anindilykwa.
(15) jungarra bawa-tha
warmgal-d
(Kayardild)
big(NOM) blow-ACT
wind-NOM
'The wind's blowing strong.' (Evans 1995: 256)
(16) jirrka-rrnga-maru-tha
kurrka-tha kunawuna-ya
north-BOUND-VD-ACT take-ACT child-MLOC
barrngka-y, (Kayardild)
kurndaji
jirrkur-ung-ka
mirrayala-th,
waterlily-MLOC
sandhill(NOM) north-ALL-NOM
make-ACT
Nalkardarrawuru
(name) 
'Nalkardarrawuru took the baby waterlilies to the beach to the north (Bentinck Island, from Fowler Island), and made a sandhill way to the north.' (ibid.)

\section{Conclusions}

As a conclusion, we would like to highlight again that the main results achieved here demonstrate that a rich semantic annotation scheme is required in order to make sense of the interplay between aspectuo-temporal parameters and contexts, in order to reveal the variety of constraints underlying the temporal interpretation of aspectuo-temporally deficient tense forms ('zero tenses'). We have established that change-of-state/perfectivity are the best predictors of temporal anchoring for the Anindilyakwa REAL-V- $\varnothing$ inflectional paradigm, rather than focusing on event structural parameters à la Vendler (1957). This contrasts with most existing past analyses. We have also mentioned - and demonstrated - that our results were probably influenced by the predominance of past contexts in our corpus data, but argued that this probably does not affect the ranking of parameters here established. Of course, future developments will necessary to fully back, and potentially improve upon, the results of this pilot study. It is highly desirable to expand our corpus towards non-narrative genres, so as to be able to assess the impact of textual genres in general on the quantitative results exposed above. We have also shown that this type of simultaneous temporal and aspectual deficiency is not an isolated fact in Australian tense systems, and that comparative work is clearly required to fully understand the intricacies of aspectuo-temporal underspecification.

\section{Patents}

Supplementary Materials: Our corpora and analytical results, plus some supplementary tables \& vizualizations, are available online at https://cloud.llf-paris.fr/nextcloud/s/yHNeLig7Bnf42by.

Author Contributions: Corpus constitution: J. Bednall; corpus annotation: P. Caudal \& J. Bednall; quantitative analysis: P. Caudal; original draft preparation: P. Caudal; writing, review and editing: P. Caudal \& J. Bednall. All authors have read and agreed to the published version of the manuscript.

Funding: This research was funded by the ARC Centre of Excellence for the Dynamics of Language (Project ID: CE140100041), the Labex Empirical Foundations of Linguistics (Agence Nationale de la Recherche programme Investissements d'Avenir, ANR-10LABX-0083), especially subprojects GD4, GL3 and MEQTAME (Strands 3 and 2) (CI: Patrick Caudal) (2010-), the CNRS FEMIDAL ('Formal / Experimental Methods and In-depth Description of Australian Indigenous Languages') International Research Project (2021-) (CI: Patrick Caudal),, an Australian Government Research Training Program Scholarship (James Bednall), the School of Literature, Languages and Linguistics at the Australian National University, and the Laboratoire de Linguistique Formelle (LLF) UMR7110 at Université de Paris (formerly Université Paris Diderot). 
Institutional Review Board Statement: Data collection for this study was approved by the Human Research Ethics Committee at the Australian National University (Protocol 2015/143) and the Anindilyakwa Services Aboriginal Corporation.

Informed Consent Statement: Informed consent was obtained from all subjects involved in the study.

Data Availability Statement: Recordings cited here are archived with the Pacific and Regional Archive for Digital Sources in Endangered Cultures (PARADISEC) (https://catalog.paradisec.org.au/collections/JRB1). Legacy recordings cited here are archived with the Australian Institute of Aboriginal and Torres Strait Islander Studies (Groote_E01 Collection, Waddy_J01 Collection, Waddy_J02 Collection).

Acknowledgments: We are indebted to the Warnumamalya people of the Groote Eylandt archipelago, who have generously and patiently shared their Anindilyakwa language with us. For this paper, we are particularly thankful to Judy Lalara, Sylvia Tkac and Carol Wurramara.

Conflicts of Interest: The authors declare no conflict of interest. The funders had no role in the design of the study; in the collection, analyses, or interpretation of data; in the writing of the manuscript, or in the decision to publish the results.

\section{References}

Alotaibi, Yasir. 2020. Verb Form and Tense in Arabic. International Journal of English Linguistics 10. $284-300$. https://doi.org/10.5539/ijel.v10n5p284.

Asher, Nicholas \& Alex Lascarides. 2003. Logics of Conversation. Cambridge: Cambridge University Press.

Asher, Nicholas, Laurent Prévot \& Laure Vieu. 2007. Setting the Background in Discourse. Discours 1. http://discours.revues.org/301.

Baker, Mark \& Lisa Travis. 1997. Mood as Verbal Definiteness in a “Tenseless” Language. Natural Language Semantics 5(3). $213-269$. https://doi.org/10.1023/A:1008262802401.

Bednall, James. 2020. Temporal, aspectual and modal expression in Anindilyakwa, the language of the Groote Eylandt archipelago, Australia. Canberra / Paris: ANU \& Université de Paris PhD Thesis.

Bittner, Maria. 2005. Future Discourse in a Tenseless Language. Journal of Semantics 22(4). 339-387. https://doi.org/10.1093/jos/ffh029.

Bittner, Maria. 2008. Aspectual universals of temporal anaphora. In Susan Rothstein (ed.), Theoretical and Crosslinguistic Approaches to the Semantics of Aspect, 349-385. Amsterdam / Philadelphia: John Benjamins.

Bochnak, M. Ryan. 2016. Past time reference in a language with optional tense. Linguistics and Philosophy 39(4). 247-294. https://doi.org/10.1007/s10988-016-9191-6.

Bochnak, M Ryan, Vera Hohaus \& Anne Mucha. 2019. Variation in Tense and Aspect, and the Temporal Interpretation of Complement Clauses. Journal of Semantics 36(3). 407-452. https://doi.org/10.1093/jos/ffz008.

Bohnemeyer, Jürgen. 2002. The Grammar of Time Reference in Yukatek Maya. München: Lincom Europa.

Bohnemeyer, Jürgen. 2009. Temporal anaphora in a tenseless language. In Wolfgang Klein \& Ping Li (eds.), The Expression of Time, 83-128. Berlin, Boston: De Gruyter Mouton. https://doi.org/10.1515/9783110199031.83. http://www.degruyter.com/abstract/books/9783110199031/9783110199031.83/9783110199031.83.xml (21 July, 2018).

Bui, Thuy. 2019. Temporal reference in Vietnamese. In Nigel Duffield, Trang Phan \& Tue Trinh (eds.), Interdisciplinary perspectives on Vietnamese linguistics, 115-140. Amsterdam: John Benjamins.

Bybee, Joan L. 1990. The grammaticization of zero: asymmetries in tense and aspect systems - Vol. 3 No. 1, 1990 - Joan L. Bybee. La Trobe working papers in linguistics 3(1). 1-14.

Carolan, Elizabeth. 2015. An Exploration of Tense in Chuj. ScriptUM : la revue du colloque VocUM (1). https://scriptum.vocum.ca/index.php/scriptum/article/view/25 (25 November, 2021).

Carroll, Matthew Jay. 2016. The Ngkolmpu Language with special reference to distributed exponence. Canberra: Australian National University PhD Thesis. https://openresearch-repository.anu.edu.au/handle/1885/116801 (12 March, 2020).

Carruthers, Janice. 2005. Oral Narration in Modern French: a Linguistic Analysis of Temporal Patterns. Oxford: Legenda.

Caudal, Patrick. 1999. Computational Lexical Semantics Incrementality And The So-Called Punctuality Of Events. In Proceedings of the 37th annual meeting of the Association for Computational Linguistics on Computational Linguistics, 497-504. Stroudsburg, PA.: Association for Computational Linguistics. http://clair.eecs.umich.edu/aan/paper.php?paper_id=P99-1064 (14 January, 2016).

Caudal, Patrick. 2010. Tense switching in French oral narratives. In Janice Carruthers \& Maeve McCusker (eds.), The "Conte" - Oral and written dynamics, 235-260. Oxford: Peter Lang.

Caudal, Patrick. 2012. Pragmatics. In Robert Binnick (ed.), The Oxford Handbook of Tense and Aspect, 269-305. Oxford / New York: Oxford University Press. 
Caudal, Patrick. 2015. Mort d'un passé sous-spécifié, naissance d'un passé perfectif : évolution du passé simple, 13e-15e siècle. In Anne Carlier, Michèle Goyens \& Béatrice Lamiroy (eds.), Le français en diachronie: nouveaux objets et méthodes, 373-404. Bern: Peter Lang.

Caudal, Patrick. 2022. On so-called 'tense uses' in French as context-sensitive constructions. In Martin Becker \& Jakob Egetenmeyer (eds.), Tense, aspect and discourse structure, 20p. Berlin: De Gruyter.

Caudal, Patrick, Alan Dench \& Laurent Roussarie. 2012. A semantic type-driven account of verb-formation patterns in Panyjima. Australian Journal of Linguistics 32(1). 115-155. https://doi.org/10.1080/07268602.2012.658740.

Caudal, Patrick, Robert Mailhammer \& James Bednall. 2019. A comparative account of the Iwaidja and Anindilyakwa modal systems. Conference talk presented at the ALW2019 (Australian Languages Workshop), Camp Marysville, VIC.

Caudal, Patrick \& David Nicolas. 2005. Types of degrees and types of event structures. In Claudia Maienborn \& Angelika Wöllstein (eds.), Event Arguments: Foundations and Applications, 277-300. Tübingen: Niemeyer.

Caudal, Patrick \& Marie-Eve Ritz. 2012. Discourse structure and the perfective evolution of the Australian Present Perfect: some new hypotheses. In Chiyo Nishida \& Cinzia Russi (eds.), Building a bridge between linguistic communities of the Old and the New World: Current research in tense, aspect, mood and modality (Cahiers Chronos 25), vol. 25, 69-89. Amsterdam / New York: Rodopi.

Caudal, Patrick \& Laurent Roussarie. 2005. Aspectual Viewpoints, Speech Act Functions and Discourse Structure. In Paula Kempchinsky \& Roumyana Slabakova (eds.), Aspectual Inquiries (Studies in Natural Language and Linguistic Theory 62), 265-290. Dordrecht: Springer. https://doi.org/10.1007/1-4020-3033-9_12. http://link.springer.com/chapter/10.1007/1-4020-3033-9_12 (1 March, 2016).

Chen, Sherry Yong \& E. Matthew Husband. 2018. Contradictory (forward) lifetime effects and the non-future tense in Mandarin Chinese. Proceedings of the Linguistic Society of America 3(1). 6-14. https://doi.org/10.3765/plsa.v3i1.4296.

Craig, Colette Grinevald. 1977. The Structure of Jacaltec. Austin: University of Texas Press.

De Wit, Astrid. 2016. The Present Perfective Paradox across Languages. Oxford: Oxford University Press.

Department of Infrastructure, Transport, Regional Development and Communications, Australian Institute of Aboriginal and Torres Strait Islander Studies \& Australian National University. 2020. National Indigenous Languages Report 2020. Available online: https://www.arts.gov.au/what-we-do/indigenous-arts-and-languages/national-indigenous-languages-report (accessed on 24 September 2021). Canberra, ACT: Australian Government.

Dowty, David R. 1986. The Effects of Aspectual Class on the Temporal Structure of Discourse: Semantics or Pragmatics? Linguistics and Philosophy 9(1)(1). 37-62.

Duffield, Nigel. 2007. Aspects of Vietnamese clausal structure: separating tense from assertion. Linguistics 45(4). 765-814. https://doi.org/10.1515/LING.2007.023.

England, Nora C. 1983. A Grammar of Mam, A Mayan Language. Austin: University of Texas Press.

Evans, Nicholas. 1995. A Grammar of Kayardild. With Historical-Comparative Notes on Tangkic. Berlin: Mouton de Gruyter.

Haspelmath, Martin. 2021. Explaining grammatical coding asymmetries: Form-frequency correspondences and predictability. Journal of Linguistics. Cambridge University Press 57(3). 605-633. https://doi.org/10.1017/S0022226720000535.

Landman, Fred. 1989a. Groups, II. Linguistics and Philosophy. Springer 12(6). 723-744.

Landman, Fred. 1989b. Groups, I. Linguistics and Philosophy 12(5). 559-605. https://doi.org/10.1007/BF00627774.

Lascarides, Alex \& Nicholas Asher. 1993a. Temporal Interpretation, Discourse Relations and Commonsense Entailment. Linguistics and Philosophy 16(5). 437-493.

Lascarides, Alex \& Nicholas Asher. 1993b. A Semantics and Pragmatics for the Pluperfect. Association for Computational Linguistics.

Lascarides, Alex \& Jon Oberlander. 1993. Temporal Connectives in a Discourse Context. In Proceedings of the Sixth Conference on European Chapter of the Association for Computational Linguistics (EACL '93), 260-268. Stroudsburg, PA, USA: Association for Computational Linguistics. https://doi.org/10.3115/976744.976775. http://dx.doi.org/10.3115/976744.976775.

Lee, Jungmee \& Judith Tonhauser. 2010. Temporal Interpretation without Tense: Korean and Japanese Coordination Constructions. Journal of Semantics 27(3)(3). 307-341.

Lin, Jo-Wang. 2003. Temporal Reference in Mandarin Chinese. Journal of East Asian Linguistics 12. $259-311$. https://doi.org/10.1023/A:1023665301095.

Lin, Jo-wang. 2010. A Tenseless Analysis of Mandarin Chinese Revisited: A Response to Sybesma 2007. Linguistic Inquiry. The MIT Press 41(2). 305-329.

Mailhammer, Robert \& Patrick Caudal. 2019. Linear Lengthening Intonation in English on Croker Island: identifying substrate origins. JournaLIPP 6. 40-56.

Malchukov, Andrej. 2009. Incompatible Categories : Resolving the "Present Perfective Paradox." In Lotte Hogeweg, Helen de Hoop, \& Andrej Malchukov (eds.), Cross-linguistic semantics of tense, aspect, and modality (Linguistik Aktuell/Linguistics Today), vol. 148, 13-33. Amsterdam: Benjamins.

Mansfield, John. 2020. Murrinhpatha Morphology and Phonology. Murrinhpatha Morphology and Phonology. Berlin: De Gruyter Mouton. https://www.degruyter.com/view/title/514377 (28 October, 2020).

Martin, Fabienne. 2019. Non-culminating accomplishments. Language and Linguistics Compass 13(8). 1-20. https://doi.org/10.1111/lnc3.12346.

Matthewson, Lisa. 2006. Temporal semantics in a superficially tenseless language. Linguistics and Philosophy 29(6). 673-713. https://doi.org/10.1007/s10988-006-9010-6. 
Mucha, Anne. 2012. Temporal reference in a genuinely tenseless language: The case of Hausa. Semantics and Linguistic Theory 22(0). 188-207. https://doi.org/10.3765/salt.v22i0.3084.

Mucha, Anne. 2013. Temporal interpretation in Hausa. Linguistics and Philosophy 36(5). 371-415. https://doi.org/10.1007/s10988-0139140-6.

Nash, Léa. 2017. The Structural Source of Split Ergativity and Ergative Case in Georgian. In Jessica Coon, Diane Massam \& Lisa deMena Travis (eds.), The Oxford Handbook of Ergativity, 175-200. Oxford: Oxford University Press.

Nishiyama, Atsuko \& Jean-Pierre Koenig. 2010. What is a perfect state? Language 86(3). 611-646. https://doi.org/10.1353/lan.2010.0014.

Nordlinger, Rachel \& Patrick Caudal. 2012. The tense, aspect and modality system in Murrinh-Patha. Australian Journal of Linguistics 32(1). 73-113. https://doi.org/10.1080/07268602.2012.657754.

Pancheva, Roumyana \& Maria Luisa Zubizarreta. 2020. Temporal reference in the absence of tense in Paraguayan Guaraní. In Mariam Asatryan, Yixiao Song \& Ayana Whitmal (eds.), NELS 50: proceedings of the fiftieth Annual Meeting of the North East Linguistic Society: October 25-27, 2019, Massachusetts Institute of Technology. Cambridge, MA.: GLSA, University of Massachussets/Amherst.

Ritter, Elizabeth \& Martina Wiltschko. 2014. The composition of INFL: An exploration of "tense, tenseless" languages, and "tenseless" constructions. Natural Language \& Linguistic Theory. Springer 32(4). 1331-1386.

Round, Erich R. 2013. Kayardild Morphology and Syntax. Oxford: Oxford University Press.

Shaer, Benjamin. 2003. Toward the tenseless analysis of a tenseless language. In Jan Anderssen, Paula Meéndez-Benito \& Adam Werle (eds.), Proceedings of SULA 2 (Conference on the Semantics of Under-Represented Languages in the Americas), 139-156. Amherst, MA: GLSA (Graduate Linguistics Students' Association).

Singler, John Victor (ed.). 1990. Pidgin and Creole Tense-mood-aspect Systems. John Benjamins Publishing.

Smith, Carlota. 1991. The Parameter of Aspect. Dordrecht: Kluwer.

Smith, Carlota S. \& Mary S. Erbaugh. 2005. Temporal interpretation in Mandarin Chinese. De Gruyter Mouton 43(4). 713-756. https://doi.org/10.1515/ling.2005.43.4.713.

Smith, Carlota S., Ellavina T. Perkins \& Theodore B. Fernald. 2007. Time in Navajo: Direct and Indirect Interpretation. International Journal of American Linguistics. The University of Chicago Press 73(1). 40-71. https://doi.org/10.1086/518334.

Street, Chester S. 1996. Tense, aspect and mood in Murrinh-Patha. In William McGregor (ed.), Studies in Kimberley languages in honour of Howard Coate, 205-225. München: Lincom Europa.

Tagliamonte, Sali A. \& Shana Poplack. 1993. The Zero-Marked Verb : Testing the Creole Hypothesis. Journal of Pidgin and Creole Languages 8(2). 171-206. https://doi.org/10.1075/jpcl.8.2.02tag.

Tonhauser, Judith. 2006. The Temporal Semantics of Noun Phrases: Evidence from Guarani. Stanford University Thesis. http://lear.unive.it/jspui/handle/11707/4289 (25 November, 2021).

Tonhauser, Judith. 2011. Temporal reference in Paraguayan Guaraní, a tenseless language. Linguistics and Philosophy 34(3). 257-303. https://doi.org/10.1007/s10988-011-9097-2.

Tonhauser, Judith. 2015. Cross-Linguistic Temporal Reference. Annual Review of Linguistics 1(1). 129-154. https://doi.org/10.1146/annurev-linguist-030514-124923.

Toosarvandani, Maziar. 2021. Encoding Time in Tenseless Languages: The View from Zapotec. In D. K. E. Reisinger \& Marianne Huijsmans (eds.), Proceedings of the 37th West Coast Conference on Formal Linguistics, 21-41. Somerville, MA: Cascadilla Proceedings Project. http://www.lingref.com/cpp/wccfl/37/abstract3512.html (25 November, 2021).

Vendler, Zeno. 1957. Verbs and Times. The Philosophical Review 6(2). 143-160. 